\title{
El futuro del currículum: La educación y el conocimiento en la era digital
}

Ben Williamson Madrid: Ediciones Morata, 2019 ( $1^{\text {era }}$ edición español). 122 páginas.

María José Umaña Altamirano*

¿Cuáles son los factores sociales, más allá de la academia y del aula, que informan los cambios curriculares en la era digital? ¿Cuánto y cómo influyen las transformaciones de los sistemas económicos, políticos y culturales? Y, lo más importante, ¿de qué forma estos currículos pretenden configurar las mentes, las ideas, las identidades y las actuaciones de los jóvenes?

Son estas y otras las preguntas que intenta responder Ben Williamson, académico de la Universidad de Stirling en Reino Unido, e investigador en las áreas de política educativa y tecnología educativa, en su libro El futuro del currículum: La educación y el conocimiento en la era digital.

En siete capítulos el autor expone las principales ideas que se desprenden del estudio de nueve propuestas curriculares que incluyen el uso de medios digitales, impulsadas por organismos independientes del sistema educativo tradicional. En este contexto, plantea la interrogante respecto de las implicancias en la formación de los estudiantes, debido a que las entidades que guían la construcción del curriculum responden a un nuevo pensamiento de "sociedad".

El estudio busca conocer los elementos que estas innovaciones curriculares o microreformas seleccionan del pasado, cómo estos elementos representan el presente y qué ideas generan sobre el futuro,

* Chilena. Licenciada en Artes mención Teoría e Historia del Arte, Universidad de Chile. Magister en Educación mención Informática Educativa, Universidad de Chile. Email: mariajoseumana@gmail.com 
para poder finalmente ir construyendo una nueva forma de pensar el currículo escolar en la era digital.

En el primer capítulo, el autor introduce el tema, y advierte que, históricamente, el curriculum se ha adaptado a los cambios y necesidades de la sociedad; por ello, la tesis principal de este informe apunta a que todo curriculum representa una forma de entender el pasado y, asimismo, es capaz de suscitar una visión del futuro. En este escenario, y considerando la fuerte presencia de los medios y aprendizajes digitales en el sistema educativo, el autor considera necesario estudiar los alcances prácticos y conceptuales de las nuevas propuestas, para responder a la inquietud respecto del futuro del currículo en la era digital.

Todas las iniciativas analizadas ofrecen una visión de cómo se puede rediseñar el curriculum en el contexto de la era digital, fundamentando dicha reformulación en los cambios sociales y tecnológicos, tanto a nivel económico, político y cultural, que la sociedad moderna ha ido experimentando. Por ello, señala que la reforma implica no solo un cambio en las prácticas educativas sino también un cambio de orden político.

Educación centrífuga es el nombre colectivo utilizado por Williamson para referirse a los currículos prototípicos del futuro, educación caracterizada por promover una enseñanza descentralizada, distribuida y dispersada. Sus palabras claves son redes, conexiones y descentralización, además de otros términos centrífugos similares.

Los estudios de caso en los cuales se analizan los currículos prototípicos o programas I+D del curriculum, son: Enquiring Minds (EM, Mentes Inquisitivas); High Tech High (HTH, Instituto Superior de Alta Tecnología); Learning Futures (Futuros de Aprendizaje); New Basics (Nuevos Conocimientos Básicos); Opening Minds (Abrir las Mentes); Quest to Learn (Q2L, Buscar para Aprender); The Partnership for 21st Century Skills (P21, Asociación para las Destrezas del Siglo XXI); la alianza Whole Education (Enseñanza Total) y otras organizaciones educativas del "sector terciario".

La mayoría corresponde a iniciativas desarrolladas por organizaciones no gubernamentales e instituciones privadas en Estados Unidos, Inglaterra y por el Ministerio de Educación de Australia, que buscan principalmente la elaboración de currículos que permitan en los 
estudiantes el desarrollo de las competencias para enfrentar los desafíos laborales del siglo XXI.

En el segundo capítulo, "Cambio curricular y el futuro del conocimiento oficial", se ofrecen algunas nociones investigativas en torno al curriculum del futuro, se abordan los conocimientos educativos llamados "legítimos" u "oficiales", y se plantea la interrogante respecto de su validación. Por otra parte, se exponen las inquietudes que apuntan a los tipos de conocimientos que debieran ser considerados en el curriculum del futuro, cuáles son sus orígenes en el pasado y los legados culturales que representan, qué futuro contemplan y qué autoriza su inclusión. Este capítulo, además, muestra un breve resumen de los cambios curriculares en los últimos treinta años y, finalmente, ejemplos de programas curriculares actuales que han surgido producto de los cambios sociales emergentes.

El tercer capítulo se centra en las "Redes, sistemas descentralizados y futuros educativos abiertos" y busca presentar ejemplos alternativos de currículos del futuro, como Quest to Learn (Q2L), situándolos en un mundo "abierto" de complejos sistemas interconectados lejos de las instituciones y las ideas habituales de los sistemas educativos, así como también de la política y los valores que estas representan. Q2L está diseñado en torno a la idea de "diseño de juegos y sistemas", estableciendo el modelo de los videojuegos como eje del diseño curricular, con el objetivo de integrar los principios del aprendizaje efectivo en contextos altamente motivadores. De esta forma, se entiende el curriculum como un proceso emergente y de interacción.

En el capítulo "La escuela creativa y el futuro híbrido de la economía" se busca explorar cómo se construye el curriculum del futuro dentro de la educación pública para los trabajos del sector privado, utilizando como ejemplo el prototipo curricular de red de centros concertados High Tech High (HTH), cuyo objetivo es la integración de la formación técnica y académica con el fin de preparar al estudiante para ámbitos altamente tecnológicos. De esta manera, el capítulo expone cómo el futuro de la economía y el currículo del futuro se unen mediante la asociación entre lo público y lo privado, ante lo cual el autor se pregunta: ¿qué redes de organizaciones y personas, y qué conexiones transectoriales e interorganizacionales intervienen en ello, y con qué fines y propósitos? 
El quinto capítulo, "Las escuelas psicotécnicas y el futuro de la profesión educativa", analiza qué fuentes de experiencia y qué conocimientos profesionales se orientan hacia un estilo de pensamiento que permita la elaboración de un curriculum nuevo, considerando que éste es el resultado de constantes enfrentamientos acerca del conocimiento oficial y que basa su legitimidad en autoridades especializadas. Williamson apunta a los psicólogos y a los científicos informáticos como los principales expertos que intervienen en la construcción del curriculum para el futuro, obteniendo como resultado el fomento de unas "escuelas psicotécnicas", las cuales tendrían incidencia sobre la formación de las personas, en conformidad con los objetivos políticos y económicos establecidos.

En el capítulo seis, "La globalización de la cultura del aprendizaje permanente", el autor plantea que el currículo del futuro participa en la construcción de la cultura del futuro, proponiendo la cultura de internet como parte del conocimiento legitimado que se articula a través de la educación. La cultura de internet se ha ido reconociendo gradualmente como parte de la verdadera cultura del presente y, en consecuencia, se ha ido articulando como parte del escenario actual, el cual debe estar representado en el currículo del futuro. En este contexto, ¿qué se selecciona de la cultura de internet para integrarlo en el curriculum, y qué visiones culturales y valores para el futuro se establecen como "verdaderos" para los escolares?

En el último capítulo, "Construir identidades de estudiante DIY", Williamson expone cómo el curriculum transmite ideas sobre quién es el alumno y quién debería ser, proponiendo que el curriculum promueva y modele las identidades del estudiante, su mente y sus ideas.

A lo largo de los siete capítulos que componen el libro, el autor expone el currículo del futuro como la consecuencia y resultado de un estilo de pensamiento en referencia al conocimiento, las redes, la economía, la experiencia psicotécnica y los patrones culturales de la globalización.

Las diferentes perspectivas y propuestas relacionadas con el currículo del futuro demuestran la tarea del continuo debate de determinar qué conocimientos se han de enseñar en la escuela, atendiendo en gran medida al hecho de que el currículo suele encarnar o reflejar las 
realidades políticas, económicae, culturales y sociales de las que surge. En este sentido, Williamson señala que los ejemplos de los estudios de casos estudiados en este informe evidencian que el futuro del currículo está en manos de entidades que, en su mayoría, no pertenecen al sistema educativo tradicional, por lo cual las mentes y las ideas de los niños, niñas y jóvenes estarían sometidas a un nuevo estilo de pensamiento, cuyo objetivo es configurarlos, moldearlos y esculpirlos según como lo requiera la sociedad.

La propuesta del autor supone nuevos y múltiples desafíos para los docentes, los que están llamados no solo a capacitarse, sino que a ser agentes activos en el uso y desarrollo de herramientas informáticas para la educación. Es también una llamada de atención a las autoridades y tomadores de decisiones para que estas nuevas perspectivas sean incluidas en los diseños de políticas públicas educativas, y una tarea para que los investigadores locales en educación recojan y profundicen las preguntas acerca de cómo y para qué implementar el uso de nuevas tecnologías dentro de un currículo escolar, pensando en los desafíos de la era digital. 